\title{
Statistical analysis of master world records: Surprisingly minor gender differences of aging performance decay
}

\author{
Barbara Ravara ${ }^{1 *}$ Paolo Gava ${ }^{2}$, Matthew J Taylor ${ }^{3}$ and Amber L Pond ${ }^{4}$ \\ ${ }^{1} \mathrm{~A} \& \mathrm{C}$ M-C Foundation for Translational Myology, Padova, Italy \\ ${ }^{2}$ Interdepartmental Research Center of Myology, Department of Biomedical Science, University of Padova, Italy \\ ${ }^{3}$ The University of Sydney Business School, Sydney, Australia \\ ${ }^{4}$ Anatomy Department, Southern Illinois University School of Medicine, Carbondale, Il, USA
}

\begin{abstract}
Background: Certain physiological aspects of aging are significantly different between females and males. Here, our aim is to quantitate the gender-related difference in skeletal muscle power decline with age using a parametric analysis of normalized Master World Records.

Methods: Master athletes compete in age groups of 5 years, ranging from 35 to 100 years of age. Thus, their World Records are lists of $13-15$ data points, that, after a normalization procedure, can be conveniently interpolated with polynomial trend-lines having an $\mathrm{R}^{2}$ higher than 0.84 .

Results: As expected, the decline has commenced by 35 years for both women and men. Comparing normalized female and male World Records of Master athletes in 19 Track and Field events presents a surprise: despite the difference in sport events results $(\Delta \%$ is $-15.09+/-10.51 \mathrm{SD}, p=0.018$ in female vs male athletes), the normalized aging performance decay is very similar, being not statistically significant $(\Delta \%$ is $-5.52+/-4.65 \mathrm{SD}, p=0.069)$. When two age groups of Master World records are compared, Masters from 35 to 60 years of age (Group 1) and those from 65 to 100 years (Group 2), the gender differences are not significant: $\Delta \%-4.41$ $+/-4.75 \mathrm{SD}, p=0.306$ for female Group 1 , and $\Delta \%-8.87+/--7.81 \mathrm{SD}, p=0.062$ for female group 2 .
\end{abstract}

Conclusion: This lack of gender difference in aging performance decay is a unique exception to the general rule of gender differences in sports activities, suggesting that neuro-hormonal difference among genders poorly influences the aging muscle power decay. It could be hypothesized that the age-induced decline is related to some fundamental cellular mechanisms, perhaps those that control energy metabolism.

\begin{abstract}
Abbreviations: CoM: Center of Mass; $\mathrm{VO}_{2} \max$ : Maximal Oxygen Consumption
\end{abstract}

\section{Introduction}

Females and males do not age in the same manner. In particular, life expectancy is longer in women [1]. On the other hand, females have consistently weaker muscle strength when compared with coetaneous young, old and oldest males [2-4]. The World Records of Senior and Master Athletes in Track and Field competitions provide strong evidence of this seemingly obvious fact when one observes the differences in the recorded performances of male and female athletes [5]. Master Athletes are athletes competing within age groups divided into categories of five-year periods, from 35-39, 40-44, and so on, until the age of 110 years. In general agreement with previous studies [613], Gava et al. [5] reported a decline in athletic performance with age and developed some interesting conclusions when further analyzing the decline of the performances of male Master athletes in running, jumping and throwing events as revealed by the World Records. This study compared the declining trends of the male Master athletes by transforming the measured athletic performance into a parameter proportional to the power developed by the athlete in carrying out the athletic gesture. Such a parameter is a dimensionless number ranging from the maximum value of 1 (for the absolute world record, that is, those of Senior Athletes) to decreasing values with decreasing performance of the Master Athletes. This approach gets rid of the main confounding factors found in other studies of age-related performance decay such as the different lengths of clinical longitudinal studies [11], [14-16] or the use of different modalities to measure strength, power and resistance to fatigue [17]. The results of this normalization are rows of up to 16 performance parameters conveniently interpolated with polynomial trend-lines that directly compare performances of very different athletic gestures. The main conclusion of the Gava et al. study [5] using normalization was that the performance decline noted in the different Track and Field events is actually very similar in all events. In the present study, we extend the statistical analyses to both male and female Master athletes, observing 19 Track and Field competitions, and provide statistical evidence that there is only a very minor gender difference in aging performance decay.

\section{Materials and Methods}

\section{World records database}

First, the method required the creation of a database containing all of the World Records from the main disciplines of athletics: 11 track, 4

${ }^{\star}$ Correspondence to: Barbara Ravara, Interdepartmental Research Center of Myology, Department of Biomedical Science, University of Padova, Via Ugo Bassi, 58/B 35131 Padova, Italy, E-mail: barbara.ravara@unipd.it

Key words: masters world records, aging performance decay, gender differences

Received: October 05, 2019; Accepted: October 21, 2019; Published: October 25,2019 
throwing and 4 jumping events. These collated records also contained the data from all categories of the Master Athletes, both females and males (19 categories each gender). The data were collected from the official archives of world athletic associations: IAAF, International Association of Athletics Federation (http://www.iaaf.org/) [19] for absolute World Records of Senior Athletes, and the World Master Athletics (http://www.world-masters-athletics.org/) [20] for the World Records of Master Athletes. All data used in this study are public data collected in events officially recognized by the Federation of Athletics. The data are the official records valid in May 2013. All the athletic performances are "power" performances. For example, the work to displace the body of the athlete from the start to the finish line divided by the time spent is directly proportional to the power developed (i.e., the less the time, the more the power); and the distance reached by the piece of equipment in throwing is directly proportional to the kinetic energy transmitted to the equipment by the athletic action (i.e., again proportional to the physical power developed by the athlete).

Comparisons of male and female senior athlete world records: nineteen different track and field events: The reality is that the female athletes do not perform as well as the males in track and field events. This is noted by either: 1) an increased time for female athletes in the running events; 2 ) the lesser distance reached by the piece of equipment propelled by female athletes in throwing events; or 3) the shorter distance achieved by the female athletes themselves in jumping events. Here we have measured the differences in performance between male and female athletes and recorded it as negative data.

\section{Normalization procedure}

\section{One-step normalizations}

After creation of the data base, the data from each event in the Master World Records were then "normalized" with respect to each relevant absolute world record. Specifically, the data from the World Records which increase with age (such as the time for the running events) were normalized by dividing the absolute Record by the Master Record. However, the data from events for which the data increase with age (such as the height for the high jumping events and the distance for the throwing events and the long jumping events) were normalized in the opposite way: the Master Record was divided by the absolute Record. Consequently, the normalized Records of each event are a set of dimensionless values that decrease with age, from 1 (absolute Record normalized value) to 0 for a null value. With such a procedure the performances always decrease with age, in line with the usual idea of decline, regardless of the fact that the measured values of the performances increase (running) or decrease (throwing, jumping) with age. This is to allow for a consistent form of measurement across the different events which reflects the fact that increased age is generally associated with a decrease in performance.

\section{Two-step normalizations}

With jumping events, the power developed by the athletes is associated with the displacement of the Center of Mass (CoM) of their own body, which is essentially equal to the jumping length for the horizontal jumping events (e.g., Long Jump and Triple Jump), but is not proportional to the height of the cross bar in the vertical jumping events (e.g., High Jump and Pole Vault). The height of the vertical jumps is unquestionably and mainly linked to the speed of the athlete's $\mathrm{CoM}$ at the time of detachment. Such speed, according to Newton's second law of motion, depends directly on the impulse imparted to the athlete's mass at take-off. The impulse in turn depends on the athlete's ability to accelerate his CoM, a capacity that is directly linked to the power developed in the athletic gesture. For this reason (in spite of controversial objections raised by some authors; [20,21], we treat the lifting of the athlete's center of gravity in the jump as directly connected to the power developed by the athlete in the execution of the jump $[20,23]$. Indeed, when performing the vertical jumps the athlete has to raise his own CoM from a starting level of about $110-120 \mathrm{~cm}$ from the ground at the take-off point to $10-20 \mathrm{~cm}$ above the cross bar. Thus, the vertical jumping performances need a two-step normalization process in order to obtain the normalized dimensionless parameter proportional to the power developed in the performance. Despite some approximations, this method allows for a conceptually correct "normalization" of vertical jumps. The performance of Throwing events are also further normalized by taking into account the decreasing weight of the implements with the increasing age of the Master athletes.

\section{Statistical Analyses}

Statistical analyses were performed using GraphPad Prism 5.0 software (GraphPad software, La Jolla, CA, USA). The limit for statistical significance was always considered $p<0.05$.

\section{Results}

The normalized parameters of our study are derived from the World Records of Master athletes, male and female, for 19 disciplines of athletics. Each data set consists of 13-15 points, representing athletes of ages ranging from 35 to 90-100 years (Figure 1). Further each data set can be linearly interpolated with all interpolations decreasing from 1 to null (Table 1 ).

Figure 2 shows the average values of the normalized parameter for the 19 disciplines, blue for males and orange for females. Table 1 shows the $\mathrm{R}^{2}$ values of the linear interpolation of normalized Masters World records. With the exception of the $60 \mathrm{~m}$ event of male athletes, all of the slopes have an $\mathrm{R}^{2}$ higher than 0.90 , suggesting a continuous process of performance decay with age that occurs in both male and female athletes throughout life from at least the age of 35 (when the data are first gathered). The slopes of the normalized values for male (blue) and female (orange) athletes overlap, but there is a trend toward slightly higher values for the male Master Athletes; this is more evident when the 19 events are pooled (Figure 2). Table 2 shows the statistical significance of the pooled values for both the absolute and the normalized values of the progressive process of performance decay with aging. Statistically significant gender differences $(p<0.05)$ are present only when the data from the younger Master Athletes are included and the absolute values ( $\otimes \%-15$ for the Female vs Male Athletes) are compared (Table 2). After data normalization, there is a trend of $-5 \otimes \%$ for the female relative to male athletes that does not reach statistical significance. Therefore, there are no clear differences between the genders in terms of athletic performance decline across the 19 events with women and men following close trends.

\section{Discussion}

World Record holders are excellent athletes: their performances are far better than the performances of any other persons. They are perfectly healthy, perfectly trained, perfectly fit for the purpose (their event), and are $100 \%$ motivated to draw the maximum possible performance from their bodies. Thus, the results of this kind of analysis concerning the aging-related decline in physical performance of skeletal muscle reveal some indisputable elements:

1. Despite the differences in absolute performance of female and male skeletal muscles [15\% lower in females)] [2-4], the trend of 
Table 1. Linear interpolation of normalized Master World records

\begin{tabular}{|c|c|c|c|c|}
\hline \multirow[b]{2}{*}{ Event } & \multicolumn{2}{|c|}{$\mathbf{R}^{2}$} & \multicolumn{2}{|c|}{ Liner Interpolations } \\
\hline & Male & Female & Male- & Female \\
\hline $60 \mathrm{~m}$ & 0.8444 & 0.9352 & $y=-0.0080 x+1.2764$ & $y=-0.0079 x+1.2598$ \\
\hline $100 \mathrm{~m}$ & 0.9219 & 0.9501 & $y=-0.0080 x+1.2630$ & $y=-0.0099 x+1.3603$ \\
\hline $200 \mathrm{~m}$ & 0.9194 & 0.9519 & $y=-0.0089 x+1.2936$ & $y=-0.0109 x+1.3909$ \\
\hline $400 \mathrm{~m}$ & 0.9051 & 0.9606 & $y=-0.0100 x+1.3522$ & $y=-0.0106 x+1.3358$ \\
\hline $800 \mathrm{~m}$ & 0.9251 & 0.963 & $y=-0.0095 x+1.3138$ & $y=-0.0121 x+1.4480$ \\
\hline $1500 \mathrm{~m}$ & 0.9289 & 0.9362 & $y=-0.0103 x+1.3502$ & $y=-0.0093 x+1.2900$ \\
\hline 1 Mile & 0.922 & 0.9749 & $y=-0.0101 x+1.3426$ & $y=-0.0109 x+1.3688$ \\
\hline $3000 \mathrm{~m}$ & 0.9193 & 0.9372 & $y=-0.0092 x+1.2911$ & $y=-0.0095 x+1.2748$ \\
\hline $5000 \mathrm{~m}$ & 0.9114 & 0.9641 & $y=-0.0095 x+1.3103$ & $y=-0.0095 x+1.2996$ \\
\hline $10000 \mathrm{~m}$ & 0.9356 & 0.9185 & $y=-0.0086 x+1.2672$ & $y=-0.0099 x+1.3130$ \\
\hline Marathon & 0.9307 & 0.974 & $y=-0.0084 x+1.2867$ & $y=-0.0108 x+1.3734$ \\
\hline High Jump & 0.9925 & 0.985 & $y=-0.0134 x+1.3639$ & $y=-0.0147 x+1.3634$ \\
\hline Pole Vault & 0.9915 & 0.9062 & $y=-0.0133 x+1.4206$ & $y=-0.0129 x+1.2964$ \\
\hline Long Jump & 0.9894 & 0.978 & $y=-0.0105 x+1.3013$ & $y=-0.0112 x+1.2994$ \\
\hline Triple Jump & 0.9879 & 0.9764 & $y=-0.0109 x+1.3432$ & $y=-0.0114 x+1.3459$ \\
\hline Shot Put & 0.9604 & 0.9406 & $y=-0.0135 x+1.3904$ & $\mathrm{y}=-0.0130 \mathrm{x}+1.2883$ \\
\hline Discus Throw & 0.9596 & 0.9658 & $y=-0.0141 x+1.4278$ & $y=-0.0151 x+1.4806$ \\
\hline Hammer Throw & 0.9645 & 0.9554 & $y=-0.0151 x+1.4806$ & $y=-0.0132 x+1.2875$ \\
\hline Javelin Throw & 0.9765 & 0.9437 & $y=-0.0141 x+1.3896$ & $y=-0.0134 x+1.3041$ \\
\hline
\end{tabular}

Table 2. Statistical analysis of absolute values and normalized values of Senior and Master World Records

\begin{tabular}{|c|c|c|c|c|}
\hline $\begin{array}{l}2013 \text { Data Base of Senior and } \\
\text { master's 35-100 years Records }\end{array}$ & $\begin{array}{c}\text { Male } \\
(\text { mean } \pm \text { SD })\end{array}$ & $\begin{array}{c}\text { Female } \\
(\text { mean } \pm \text { SD })\end{array}$ & $\begin{array}{l}\text { Difference }(\Delta \%) \\
\quad(\text { mean } \pm \text { SD })\end{array}$ & $\begin{array}{c}\text { t-test } \\
(p)\end{array}$ \\
\hline Absolute values & $274.41 \pm 573.62$ & $266.44 \pm 556.45$ & $-15.09 \pm-10.51$ & 0.018 \\
\hline Normalized values & $0.657 \pm 0.263$ & $0.634 \pm 0.269$ & $-5.52 \pm-4.65$ & 0.069 \\
\hline \multicolumn{5}{|l|}{ Group 1 Masters $35-60$ years } \\
\hline Absolute values & $221.35 \pm 431.05$ & $246.29 \pm 491.05$ & $-16.25 \pm-6.29$ & 0.004 \\
\hline Normalized values & $0.861 \pm 0.112$ & $0.825 \pm 0.132$ & $-4.41 \pm-4.75$ & 0.306 \\
\hline \multicolumn{5}{|l|}{ Group 2 Masters $65-100$ years } \\
\hline Absolute values & $329.17 \pm 686.94$ & $295.40 \pm 491.05$ & $-19.58 \pm-13.57$ & 0.075 \\
\hline Normalized values & $0.471 \pm 0.158$ & $0.446 \pm 0.135$ & $-8.87 \pm-7.81$ & 0.062 \\
\hline
\end{tabular}

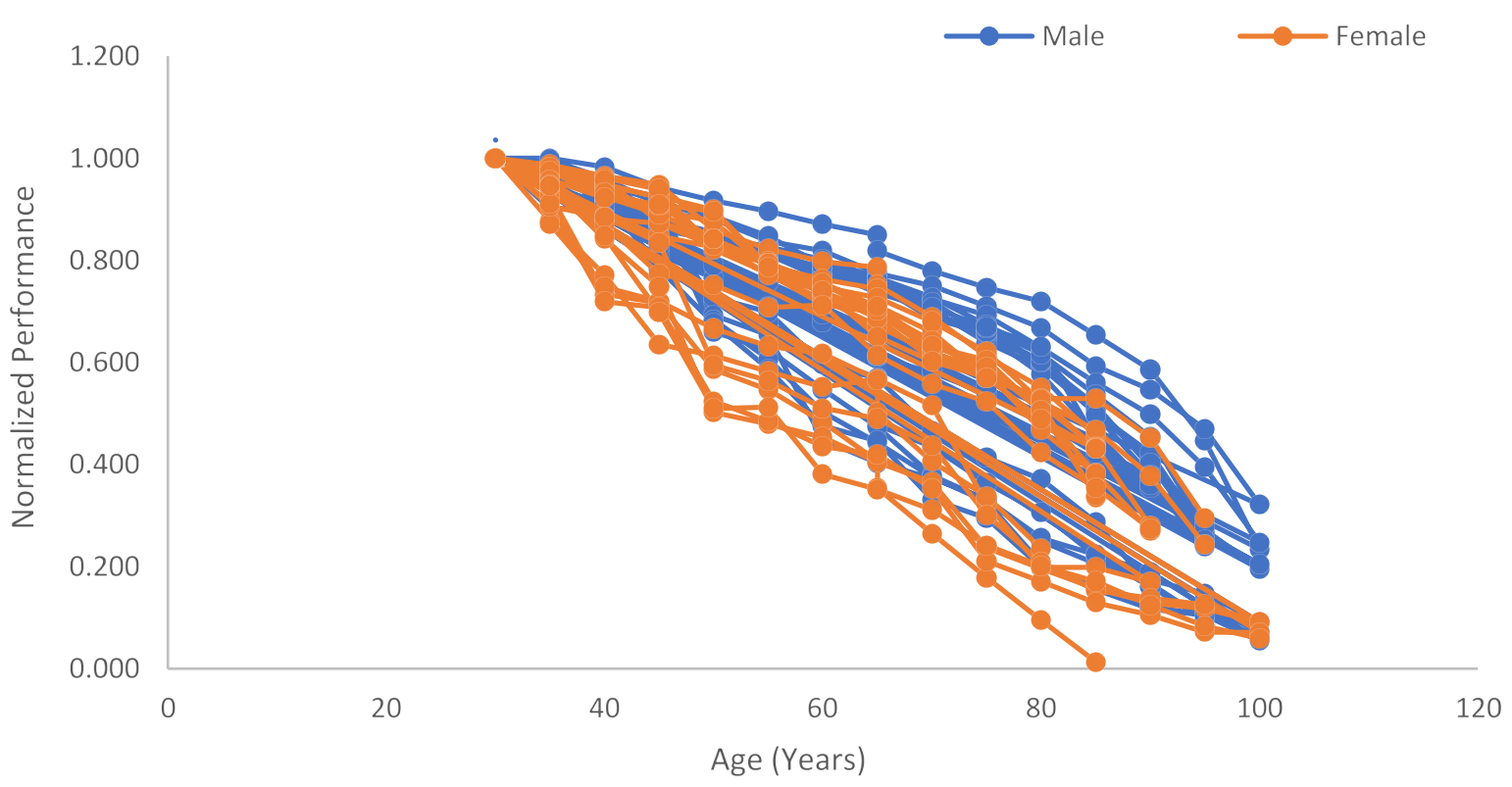

Figure 1. Normalized Master Records. Male athletes in blue, female athletes in orange. The dotted Trend Lines represent the mean of the 19 Events. 


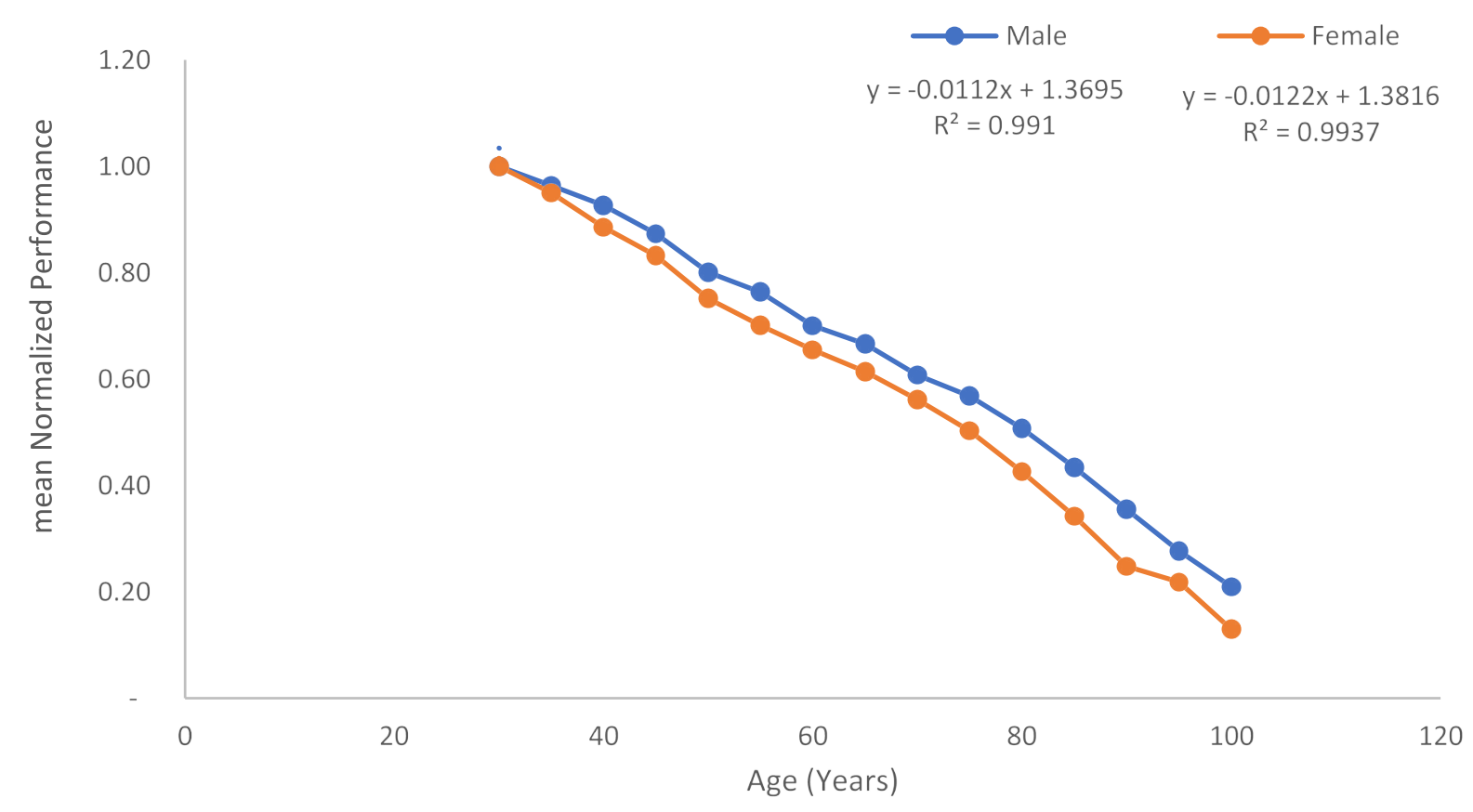

Figure 2. Normalized Master Records. Male athletes in blue, female athletes in orange. The dotted Trend Lines represent the mean of the 19 Events.

performance decline with age is very similar, if not identical, for the two genders.

2. The dimensionless parametric analysis does not reveal any unexpected peculiarity, in agreement with previous analyses using different approaches $[6,8][10-12]$.

Based on the absence of strong evidence concerning the mechanisms related to gender differences in terms of neuro-humoral physiology, it could be hypothesized that the aging decline is related to some fundamental cellular mechanisms, specifically, those that control energy metabolism [26-31]. Emerging also are the roles of epigenetic mechanisms, (i.e., of acquired mutations in gene expression that may regulate the roles of master genes of energy metabolism; 32-37). Among the main physiological determinants of endurance performance, the maximal oxygen consumption (VO2max) appears to be the parameter that is most altered by age $[24,38]$. Interestingly, these same mechanisms are present as pathogenic factors in many disorders that present behaviors described as "early or premature aging" [39-41]. This opens new perspectives for anti-aging countermeasures based on volitional exercise, $[12,13]$ or on other physical rehabilitation approaches [42-52]. The reasons for the observed minor gender inequalities in aging decline are all to be clarified, despite an immense literature in aging gender differences [1-5] [12-14] [24-28] [53,54]. On the other hand, the observed minor differences in gender-related performance decay are associated with biological mechanisms, but they can be equally due to socio-cultural factors, given the differences in the social life of females and males in all ages and in all cultures. In conclusion, taken together, the quantitative analyses of World Records of Master athletes here described suggest that there are no significant differences in the "age-related decline in athletic performance" between females and males. This is something fully unexpected in genderrelated sports behaviors. Implications may have long-term influences on biology, physiopathology and managements of aging per se and of its complications.

\section{Authors contributions}

Paolo Gava played a main role in the conception and data acquisition, while Barbara Ravara, Matthew J Taylor and Amber L Pond participated in analyses of data and in drafting and finalizing the manuscript.

\section{Acknowledgment}

The Authors thank colleagues of the Interdepartmental Research Center of Myology, Department of Biomedical Science, University of Padova, Italy and of the A\&C M-C Foundation for Translational Myology, Padova, Italy for discussions and critical readings.

\section{Funding}

BR thanks for support A\&C M-C Foundation for Translational Myology, Padova, Italy and the Interdepartmental Research Center of Myology, Department of Biomedical Science, University of Padova, Italy. Research reported in this publication was supported in part by the National Institute of Arthritis and Musculoskeletal and Skin Diseases of the National Institutes of Health under Award Number NIH NIAMS 1R03AR053706-01A2 to ATP. The content is solely the responsibility of the authors and does not necessarily represent the official views of the National Institutes of Health.

\section{Conflict of interest}

The authors declare no financial, personal, or other conflicts of interest.

\section{Ethical publication statement}

We confirm that we have read the Journal's position on issues involved in ethical publication and affirm that this report is consistent with those guidelines.

\section{References}

1. Barford A, Dorling D, Davey Smith G, Shaw M (2006) Life expectancy: women now on top everywhere. BMJ 332: 808. [Crossref] 
2. Lewis DA, Kamon E, Hodgson JL (1986) Physiological differences between genders. Implications for sports conditioning. Sports Med 3: 357-69. [Crossref]

3. Hunter SK, Stevens AA (2013) Sex differences in marathon running with advanced age: physiology or participation? Med Sci Sports Exerc 45: 148-156. [Crossref]

4. Mascherini G, Castizo-Olier J, Irurtia A, Petri C, Galanti G (2018) Differences between the sexes in athletes' body composition and lower limb bioimpedance values. Muscles Ligaments Tendons J 7: 573-581 [Crossref]

5. Gava P, Kern H, Carraro U (2015) Age-associated power decline from running, jumping, and throwing male Masters World Records. Exp Aging Res 41: 115-35. [Crossref]

6. Baker AB, Tang YQ, Turner MJ (2003) Percentage decline in masters superathlete track and field performance with aging. Exp Aging Res 29: 47-65. [Crossref]

7. Baker AB, Tang YQ (2010) Aging performance for masters records in athletics, swimming, rowing, cycling, triathlon and weightlifting. Exp Aging Res 36: 453-77. [Crossref]

8. Böttiger LE (1973) Regular decline in physical working capacity with age. Br Med J 3: 270-271. [Crossref]

9. Edmunds K, Gíslason M, Sigurðsson S, Guðnason V, Harris T, et al. (2018) Advanced quantitative methods in correlating sarcopenic muscle degeneration with lower extremity function biometrics and comorbidities. PLoS One 13: e0193241 [Crossref]

10. Frontera WR, Hughes VA, Fielding RA, Fiatarone MA, Evans WJ, et al. (2000) Aging of skeletal muscle: a 12-yr longitudinal study. J Appl Physiol 88: 1321-1326. [Crossref]

11. Grassi B, Cerretelli P, Narici MV, Marconi C (1991) Peak anaerobic power in master athletes. Eur J Appl Physiol Occup Physiol 62: 394-399. [Crossref]

12. Mitchell WK, Williams J, Atherton P, Larvin M, Lund J, et al. (2012) Sarcopenia, dynapenia, and the impact of advancing age on human skeletal muscle size and strength; a quantitative review. Front Physiol 3: 260 [Crossref]

13. Larsson L, Degens H, Li M, Salviati L, Lee YI, et al. (2019) Sarcopenia: Aging-Related Loss of Muscle Mass and Function. Physiol Rev 99: 427-511. [Crossref]

14. Metter EJ, Conwit R, Tobin J, Fozard JL (1997) Age-associated loss of power and strength in the upper extremities in women and men. J Gerontol A Biol Sci Med Sci 52: B267-276. [Crossref]

15. Skelton DA, Greig CA, Davies JM, Young A (1994) Strength, power and related functional ability of healthy people aged 65-89 years. Age Ageing 23: 371-377. [Crossref]

16. Young BW, Starkes JL (2005) Career-span analyses of track performance: Longitudinal data present a more optimistic view of age-related performance decline. Exp Aging Res 31: 69-90. [Crossref]

17. Runge M, Rittweger J, Russo CR, Schiessl H, Felsenberg D (2004) Is muscle power output a key factor in the age-related decline in physical performance? A comparison of muscle cross section chair-rising test and jumping power. Clin Physiol Funct Imaging 24: 335-340. [Crossref]

18. International Association of Athletics Federation Available at http://www.iaaf.org/

19. World Master Athletics available at http://www.world-masters-athletics.org /

20. Winter EM (2005) Jumping: Power or Impulse? Med Sci Sports Exerc 37: 523

21. Knudson DV (2009) Correcting the use of the term "power" in the strength and conditioning literature. J Strength Cond Res 23: 1902-1908. [Crossref]

22. Samozino P, Rejc E, Di Prampero E, Belli A, Morin JB (2012) Optimal Force-Velocity Profile in Balistic Movements - Altius: Citius or Fortius? Med Sci Sports Exerc 44: 313-22. [Crossref]

23. Canavan PK, Vescovi JD (2004) Evaluation of Power Prediction Equations: Peak Vertical Jumping Power in Women. Med Sci Sports Exerc 36: 1589-1593. [Crossref]

24. Lepers R, Stapley PJ (2016) Master Athletes Are Extending the Limits of Human Endurance. Front Physiol 7: 613. [Crossref]

25. Coast JR, Blevins JS, Wilson BA (2004) Do gender differences in running performance disappear with distance? Can J Appl Physiol 29: 139-145. [Crossref]

26. Tezze C, Romanello V, Desbats MA, Fadini GP, Albiero M, et al. (2017) AgeAssociated Loss of OPA1 in Muscle Impacts Muscle Mass, Metabolic Homeostasis, Systemic Inflammation, and Epithelial Senescence. Cell Metab 25: 1374-1389 [Crossref]
27. Romanello V, Scalabrin M, Albiero M, Blaauw B, Scorrano L, et al. (2019) Inhibition of the Fission Machinery Mitigates OPA1 Impairment in Adult Skeletal Muscles. Cells Jun 8: E597 [Crossref]

28. Favaro G, Romanello V, Varanita T, Andrea Desbats M, Morbidoni V, et al. (2019) DRP1-mediated mitochondrial shape controls calcium homeostasis and muscle mass. Nat Commun 10: 2576. [Crossref]

29. Hood DA, Memme JM, Oliveira AN, Triolo M (2019) Maintenance of Skeletal Muscle Mitochondria in Health, Exercise, and Aging. Annu Rev Physiol 81: 19-41.[Crossref].

30. Triolo M, Hood DA (2019) Mitochondrial breakdown in skeletal muscle and the emerging role of the lysosomes. Arch Biochem Biophys 661: 66-73. [Crossref]

31. Rodríguez-Nuevo A, Díaz-Ramos A, et al. (2018) Mitochondrial DNA and TLR9 drive muscle inflammation upon Opa1 deficiency. EMBO J 37. [Crossref]

32. Marroncelli N, Bianchi M, Bertin M, Consalvi S, Saccone V, et al. (2018) HDAC4 regulates satellite cell proliferation and differentiation by targeting P21 and Sharp1 genes. Sci Rep 8: 3448. [Crossref]

33. Pigna E, Renzini A, Greco E, Simonazzi E, Fulle S, et al. (2018) HDAC4 preserves skeletal muscle structure following long-term denervation by mediating distinct cellular responses. Skelet Muscle 8: 6. [Crossref]

34. Pigna E, Sanna K, Coletti D, Li Z, Parlakian A, et al. (2018) Increasing autophagy does not affect neurogenic muscle atrophy. Eur J Transl Myol 28: 7687. [Crossref]

35. Renzini A, Benedetti A, Bouchè M, et al. (2018) Culture conditions influence satellite cell activation and survival of single myofibers. Eur J Transl Myol 28: 7567. [Crossref]

36. Renzini A, Marroncelli N, Noviello C, Moresi V, Adamo S (2018) HDAC4 Regulates Skeletal Muscle Regeneration via Soluble Factors. Front Physiol 9: 1387 [Crossref]

37. Seaborne RA, Strauss J, Cocks M (2018) Human Skeletal Muscle Possesses an Epigenetic Memory of Hypertrophy. Sci Rep 8: 1898.

38. Pigna E, Berardi E, Aulino P, Rizzuto E, Zampieri S, et al. (2016) Aerobic Exercise and Pharmacological Treatments Counteract Cachexia by Modulating Autophagy in Colon Cancer. Sci Rep 6: 26991. [Crossref]

39. Carraro U, Kern H, Gava P, Hofer C, Loefler S, et al. (2017) Recovery from muscle weakness by exercise and FES: lessons from Masters, active or sedentary seniors and SCI patients. Aging Clin Exp Res 29: 579-90. [Crossref]

40. Carraro U, Gava K, Musumeci A, Baba A, F Piccione, et al. (2018) Safe Antiaging Full-Body In-Bed Gym and FES for Lazy Persons: Home In-Bed Exercises for Fighting Muscle Weakness in Advanced Age. Rehabilitation Medicine for Elderly Patients 43-51.

41. Hofer C, Loefler S, Kern H, et al (2018) Two years of FES training improves muscle fibers of thigh muscles in long-term thoracic level-complete spinal cord injury. Biol Eng Med 3: 1-5.

42. Barberi L, Scicchitano BM, Musaro A (2015) Molecular and Cellular Mechanisms of Muscle Aging and Sarcopenia and Effects of Electrical Stimulation in Seniors. Eur J Transl Myol 25: 231-236. [Crossref]

43. Cvecka J, Tirpakova V, Sedliak M, Kern H, Mayr W, et al. (2015) Physical Activity in Elderly. Eur J Transl Myol 25: 249-252. [Crossref]

44. Hamar D (2015) Universal Linear Motor Driven Leg Press Dynamometer and Concept of Serial Stretch Loading. Eur J Transl Myol 25: 215-219. [Crossref]

45. Kern H, Barberi L, Löfler S, Sbardella S, Burggraf S, et al. (2014) Electrical stimulation counteracts muscle decline in seniors. Front Aging Neurosci 6: 189. [Crossref]

46. Mayr W (2015) Neuromuscular Electrical Stimulation for Mobility Support of Elderly. Eur J Transl Myol 25: 263-268. [Crossref]

47. Mosole S, Carraro U, Kern H, Loefler S, Fruhmann H, et al. (2014) Long-term highlevel exercise promotes muscle reinnervation with age. J Neuropathol Exp Neurol 73 . 284-94. [Crossref]

48. Protasi F (2015) Mitochondria Association to Calcium Release Units is Controlled by Age and Muscle Activity. Eur J Transl Myol 25: 257-262. [Crossref]

49. Sarabon N, Löfler S, Hosszu G, Hofer C (2015) Mobility Test Protocols for the Elderly: A Methodological Note. Eur J Transl Myol 25: 253-256. [Crossref]

50. Zampieri S, Pietrangelo L, Loefler S, Fruhmann H, Vogelauer M, et al. (2015) Lifelong physical exercise delays age-associated skeletal muscle decline. J Gerontol A Biol Sci Med Sci 70: 163-173. [Crossref] 
51. Zampieri S, Mammucari C, Romanello V, et al. (2016) Physical exercise in aging human skeletal muscle increases mitochondrial calcium uniporter expression levels and affects mitochondria dynamics. Physiol Rep 4: [Crossref]

52. Tanaka H, Seals DR (2008) Endurance exercise performance in masters athletes: Ageassociated change and underlying physiological mechanisms. $J$ Physiol 586: 55-63. [Crossref]
53. Tanaka H, DeSouza CA, Jones PP, Stevenson ET, Davy KP, et al. (1985) Greater rate of decline in maximal aerobic capacity with age in physically active vs. sedentary healthy women. J Appl Physiol 83: 1947-53. [Crossref]

54. Wiswell RA, Hawkins SA, Jaque SV, Hyslop D, Constantino N, et al. (2001) Relationship between physiological loss, performance decrement, and age in master athletes. J Gerontol A Biol Sci Med Sci 56: M618-26. [Crossref]

Copyright: (C2019 Ravara B. This is an open-access article distributed under the terms of the Creative Commons Attribution License, which permits unrestricted use, distribution, and reproduction in any medium, provided the original author and source are credited. 